\title{
MULTI-TEMPORAL FEATURE EXTRACTION FOR PRECISE MAIZE AREA MAPPING USING TIME-SERIES SENTINEL 1A SAR DATA
}

\author{
Venkatesan. M. *, Pazhanivelan. S., Sudarmanian. N. S. \\ Department of Remote Sensing and GIS, Tamil Nadu Agricultural University, Coimbatore \\ *sathyavenkat2095@gmail.com
}

Commission III, WG III/10

KEY WORDS: Maize, Synthetic Aperture Radar (SAR), Sentinel 1A, Multi-temporal features Crop area estimation, Area mapping

\begin{abstract}
:
A research study was conducted to map maize area in Ariyalur and Perambalur districts of Tamil Nadu, India using multi-temporal features extracted from time-series Sentinel 1A SAR data. Multi-temporal Sentinel 1A GRD data at VV and VH polarizations and SLC products were acquired for the study area at 12 days interval and processed using MAPscape-RICE software. Multi-temporal Sentinel 1A data was used to identify the backscattering dB curve of maize crop. Analysis of temporal signatures of the crop showed minimum values at sowing period and maximum during the tasseling stage, which decreased during maturity stage of the crop. The maximum increase in the signature was observed during seedling to vegetative growth period. The signature derived from $\mathrm{dB}$ values for maize crop expressed a significant temporal behavior with the range of -21.26 to-13.18 in VH polarization and -14.05 to -6.54 in VV polarization. Considering the accuracy of SAR data to phenological variations of maize growing period, Multi-Temporal Features were extracted from multi-temporal dB images of VV and VH polarization and coherence images. Multi-Temporal Features viz., max, min, mean, max date, min date and span ratio were extracted from VV and VH polarizations of Sentinel 1A GRD and SLC data to classify maize pixels in the study area using parameterized classification approach. The overall classification accuracy was 91 percent with the kappa score of 0.82 .
\end{abstract}

\section{INTRODUCTION}

India is one of the top countries in terms of agriculture production and largest country in terms of total arable land area with $52.8 \%$ of the arable land. The income from agriculture sector in India is expected to double by 2022 due to increased investments. Reliable and real-time information on crop area and production is the need of the hour to make appropriate policy decisions to achieve the goal. Maize is one of the most important cereal crops grown in tropical and temperate regions of the world. Crop area and yield information is highly essential for sustainable agriculture management and national food security assessment. Rapid advancements in the field of Remote Sensing based earth observation technologies provides scope for improved regional crop monitoring and area estimation. Estimation of area of maize spatially will ensure effective transfer of technologies and better policy decisions to sustain production at different levels.

Crop discrimination is a critical step for most agricultural monitoring systems. Acquiring annual crop information using traditional survey methods are very difficult due to less economic efficiency, larger area, strong seasonal and spatial heterogeneity. The use of remote sensing technology is effective way to solve this issue. (Shewalkar et al., 2014). Optical remote sensing for crop monitoring has increased over the past several years and become one of the major civilian operational applications. However, several images acquired at specific times during the crop growth cycle are required to reach a suitable accuracy. This temporal constraint limits the use of optical data for operational applications because cloud cover may prevent or delay image acquisitions in many places. Space borne SAR imagery is able to observe the Earth's surface independently under cloud cover and guarantees a temporal frequency of images throughout the growing period (Boerner et al., 1987). Crop growth cycle in a season could be monitored based on the changes in SAR backscattering in response to phenological stages of particular crop. Analysis of multitemporal C-band and L-band, airborne and space-borne SAR data showed that the relations between the backscattering of crops and the vegetation biomass depend on plant type, and that there are different trends for "narrow" and "broad" leaf crops (Macelloni et al., 2001). The dielectric properties and geometric structure of the object are major influencing factors of radar backscattering which helps in object/crop identification and mapping. Availability of high-resolution Synthetic Aperture Radar sensors viz., RISAT, Sentinel, COSMO-SkyMed and TerraSAR-X, software having automated processing chain and advanced crop yield models, makes it possible to provide accurate information on crop area. COSMO-SkyMed data are available from four X-band SAR satellites with 16 day revisit period for the same satellite with same incident angle. TerraSAR-X data is provided by one X-band SAR satellite with 11 day revisit period with same observation angle at strip map mode ( $3 \mathrm{~m}$ resolution) with footprint of $30 \times 50 \mathrm{~km}$ and ScanSAR mode (10m resolution) with footprint of $100 \times 150$ $\mathrm{km}$ (Pazhanivelan et al., 2015). With the latest launches Sentinel $1 \mathrm{~A}$ and $1 \mathrm{~B}$ data is available from European Space Agency (ESA) at C-band with the spatial resolution of $5 \mathrm{~m}$ and $20 \mathrm{~m}$ with a temporal resolution of 12 days individually and 6 days in combination. A fully automated processing chain module within MAPscape-RICE software was developed in order to convert the multi-temporal space-borne SAR data to terrain-geocoded sigma-nought values (Holecz et al., 2013). Imageries from SAR satellite have become an important tool in distinguishing of agricultural crops (Blaes et al., 2006, Hoogeboom, 1983 and McNairn et al., 2014). Since different crop types may have similar reflectance properties in visible regions, the use of remote sensing technology to differentiate crops is a demanding task (Waldhoff et al., 2012). Crops having 
similar reflectance properties can only be separated from each other by multi-temporal analysis (Gomez-Chova et al., 2015) Nelson et al. (2014) used X band SAR data and successfully derived MTF (in $\mathrm{dB}$ ) from study sites of rice and used for classifying rice. The correlation between backscattering $\left(\sigma^{\circ}\right)$ and maize growth parameters exhibited that lesser frequencies were highly related to green weight, LAI and height of plant. Moreover, $\sigma^{0}$ extracted from $\mathrm{C}$-band could generate information equivalent to the general spectral vegetation index of NDVI (Inoue et al., 2014).

\section{METHODOLOGY}

The following methodology was implemented to identify and map maize area using multi-temporal features extracted from time-series Sentinel 1A SAR data and are described below in detail. First, time-series Sentinel 1A data underwent a series of basic processing steps to generate terrain-geocoded $\sigma^{\circ}$ values from GRD data and coherence images from SLC data suitable for further analysis. Then multi-temporal features were extracted from the processed data and used in parameterized classification to identify and map the maize area. Finally, the accuracy of the maize area map was assessed using ground truth data.

\section{$2.1 \quad$ Study area}

Ariyalur and Perambalur are inland districts of Tamil Nadu with an area of 1949 sq.km and 1757 sq.km, respectively. Black and red loamy are the predominant soil types in Perambalur district. Annual rainfall of the district is $908 \mathrm{~mm}$. Major crops cultivated in the district are maize, cotton, sorghum, groundnut and onion. Sugarcane and cashew are the major crops of Ariyalur district. Red sanding with scattered packets of black soil is the predominant soil type in the district.

\subsection{Satellite data}

Synthetic Aperture Radar (SAR) has the advantage of operating at wavelengths not impeded by cloud cover or lack of illumination and can acquire data over a site during day or night time. Sentinel 1A, with its C-SAR instrument can offer reliable, repeated wide area monitoring. The Sentinel 1 mission includes $\mathrm{C}$-band imaging system operating in four imaging modes with different resolutions and area coverage. It provides dual polarization capability, short revisit period and rapid product delivery. Ground Range Detected (GRD) and Single Look Complex (SLC) datasets from Sentinel 1A Synthetic Aperture Radar imaging system with $\mathrm{VV}$ and $\mathrm{VH}$ polarizations in Interferometric Wide (IW) swath mode are obtained at 12 days interval and used for crop identification and mapping in the study area. Based on the normal growing season of Maize in the study area, the data were downloaded from https://scihub.copernicus.eu/dhus/ for the period of September 2017 to January 2018 to have the full coverage during the crop growth period in the study area.

\subsection{Ground truth collection}

Ground truth points were collected during the maize growing season of the study area at different crop growth stages. Totally 135 maize points and 100 other crop points were collected during the ground survey for training and validation using random stratified sampling method.

\section{$2.4 \quad$ Pre-Processing of SAR data}

A fully automated processing chain developed by Holecz et al. (2013) was used to convert SAR GRD multi-temporal data to terrain geo-coded $\sigma^{\circ}$ values. The processing chain itself is a module within the MAPscape-RICE software. The basic processing includes the following steps.

i). Strip mosaicking: to facilitate the overall data processing and data handling, ii). Co-registration: Images acquired with

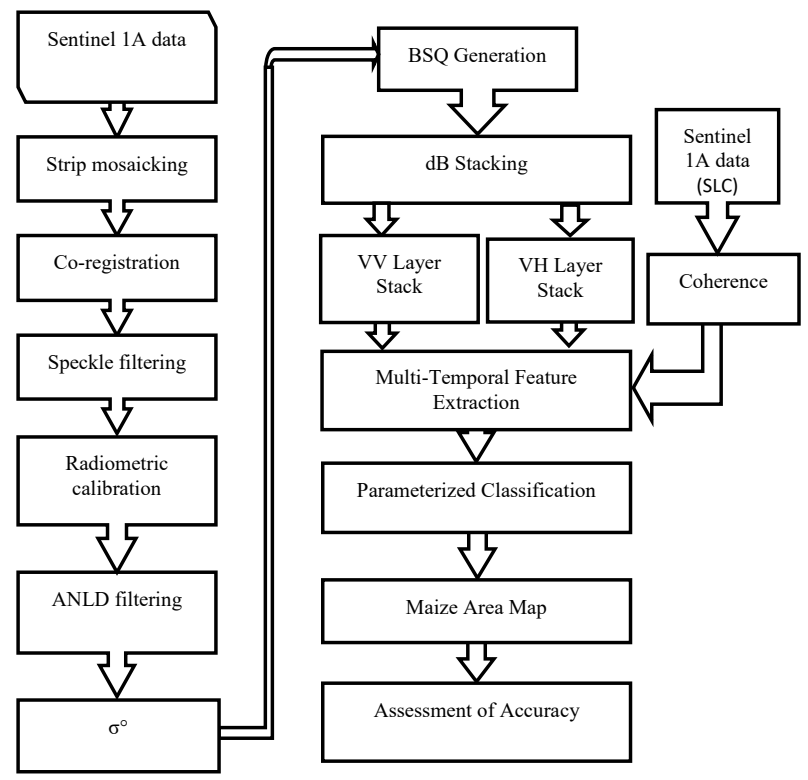

Figure 1. Flow chart of methodology

The same observation geometry were co registered in slant range geometry, iii). Time-series speckle filtering: to balance differences in reflectivity between images, iv). Terrain geocoding: Radiometric calibration and normalization, v). $A N L D$ filtering: to get smoothened homogeneous targets, vi). Removal of atmospheric attenuation: $\sigma^{\circ}$ values were corrected by means of an interpolator.

\subsection{SLC processing}

Coherence is a function of systematic spatial de-correlation and changes on the ground between two different acquisitions. It could be used to extract thematic information relevant to the ground features properties and their temporal variations. SLC (Single Look Complex) data from Sentinel 1A was used to extract the coherence. Coherence processing module in MAPscape software was used for the processing of SLC products to extract coherence, which ranges between 0 and 1 . Each coherence image is generated from data pairs acquired at consecutive satellite passes.

\subsection{Multi-Temporal Feature extraction}

Multi-temporal features viz., Minimum, Maximum, Mean, Minimum date, Maximum date and Span ratio of VV, VH polarizations and Minimum, Maximum and Mean features of coherence (cc) data were extracted using feature extraction tool in MAPscape-RICE software. These multi-temporal features are having certain range regarding maize crop, which were extracted using point sampling tool of QGIS 2.18.20.

\subsection{Crop classification}

The aim of the image classification is to categorize the image pixels into a land cover categories based on the pixel value. This 
section explains the classification methodology used in this study for maize crop area identification and classification.

\subsection{Parameterized classification}

The parameterized Classification algorithm quantitatively evaluates the variance and covariance of the category by spectral response pattern while classifying an unknown pixel. In this study, image classification was carried out using parameterized Classification algorithm with extracted multitemporal features from GRD and SLC SAR images for the identification of maize. Values extracted from multi-temporal features for maize crop was used to create training polygons. The multi-temporal features used are $\mathrm{VH}_{\max }, \mathrm{VV}_{\min }, \mathrm{VH}_{\operatorname{maxDate}}$, $\mathrm{VV}_{\text {minDate }}, \mathrm{cc}_{\min }(\mathrm{VV})$ and $\mathrm{cc}_{\text {mean }}(\mathrm{VV})$.

Coherence (cc) is a function of Systemic spatial de-correlation (i.e. the additive noise) and changes on the ground between the two acquisitions, which ranges between 0 and 1 . The training polygons are used to generate mask to include maize class while performing maize area classification using $\sigma^{\circ}$ of $\mathrm{VV}$ all dates.

\section{$2.9 \quad$ Accuracy assessment}

The error matrix and Kappa statistics are used for evaluating the classification accuracy. The class allocation of each pixel in classified image is compared with the corresponding class allocation on reference data to determine the classification accuracy. The ground reference data are used for validation and the pixels of agreement and disagreement are compiled in the form of an error matrix. The accuracy measures, such as overall accuracy, producer's accuracy and user's accuracy are estimated. Kappa coefficient is another measure of classification accuracy. It is a measure of the proportional improvement by the classifier over a purely random assignment to classes.

\section{RESULTS AND DISCUSSION}

The radar-backscattering coefficient is a measure of crop biomass, plant height, soil characteristics, water content etc. SAR data acquired for the study area was processed and analyzed to identify the crop. Training pixels from ground truth points were used to extract the temporal backscattering signatures of maize. Temporal backscattering signatures for the maize crop were generated by stacking the multi-temporal SAR data acquired during the cropping season. The signature curves showed a steep increase in backscattering during seedling to vegetative stage of the crop growth and a marginal increase in vegetative to tasseling phase followed by a decline at maturity. The similar trend was observed for VV VH polarization also. Multi-temporal backscattering coefficients of maize crop were extracted for monitoring sites and used to generate $\mathrm{dB}$ curves. Maize crop showed significant temporal behavior and large dynamic range in the crop-cultivated regions of the study area during the crop growth period. Significant increase in the backscattering coefficient was observed for first four acquisitions during the crop growth period that was typical of seedling to tassel initiation stage of the crop, which was due to the interaction of microwave radiation with the crop canopy. The backscatter minimum was observed in the initial acquisition, indicating emerging condition of the crop and the backscatter increased in succeeding acquisitions indicating the growth of the crop. The detailed analysis of temporal backscattering curve of maize crop showed a minimum $\mathrm{dB}$ values of -21.26 to -17.51 in $\mathrm{VH}$ polarization and -14.05 to 11.45 in VV polarization at the emergence stage of the maize crop. In general maize crop recorded backscattering values 21.26 to -13.18 under $\mathrm{VH}$ and -14.05 to -6.54 under VV. Lesser values under $\mathrm{VH}$ as compared to $\mathrm{VV}$ was also recorded in rice (Pazhanivelan et al., 2015) and groundnut (Deiveegan et al., 2017) under Tamil Nadu condition. The minimum of -21.26 and -14.05 under VH and VV polarization at emerge stage indicates the presence of favorable soil moisture conditions caused by sowing rains during $D_{1}$ to $D_{2}$. The mean maximum value observed during the tasseling stage of the crop was found to be 16.58 to -13.18 and -8.40 to -6.54 in $\mathrm{VH}$ and $\mathrm{VV}$ polarizations respectively. The variation in the $\mathrm{dB}$ values from seedling to tasseling stage was primarily influenced by LAI and biomass of the crop that resulted with an average addition of 5.13 and 5.04 in $\mathrm{dB}$ values of $\mathrm{VH}$ and $\mathrm{VV}$ polarizations. The decrease in backscatter values at the later stages might have been probably caused by maturity of the crop, which lowered the water content of the vegetation (Lillesand and Kiefer, 1994) or related to the vegetation biomass and or related to the reduced volumetric scattering due to maturity (Panigrahy and Mishra, 2003).

\subsection{Multi-Temporal Features extraction}

The Mean, Min, Max, Min date, Max date, and Span Ratio features of $\mathrm{VV}$ and $\mathrm{VH}$ polarizations were extracted for the study area using multi-temporal Sentinel 1A GRD data and also Min, Max and Mean values of coherence were extracted from Sentinel 1A SLC data. The values derived from $\mathrm{VH}_{\mathrm{Max}}$ and $\mathrm{VH}_{\mathrm{Min}}$ features of maize the study area were ranged from -16.80 to -13.17 and -21.26 to -16.58 respectively coinciding with the values obtained in backscatter curves also indicated the occurrence of $\mathrm{VH}_{\mathrm{Max}}$ at tasseling and $\mathrm{VH}_{\mathrm{Min}}$ at emergence date clearly different from other crops or classes indicating their capability to be used in maize area mapping. The minimum and maximum values of $\mathrm{VV}_{\text {Min }}$ and $\mathrm{VV}_{\mathrm{Max}}$ features were found to have the range of -14.05 to -8.40 and -11.45 to -6.54 whereas, the range of $\mathrm{CC}_{\mathrm{Min}}$ and $\mathrm{CC}_{\mathrm{Max}}$ features derived from coherence images are 0.019 to 0.107 and 0.073 to 0.171 respectively. Moreover, coherence between dates might have helped in precise discrimination of maize pixels from other crops grown in the study districts. The minimum date feature under VV and $\mathrm{VH}$ were $\mathrm{D}_{2}$ and $\mathrm{D}_{3}\left(13^{\text {th }}\right.$ to $25^{\text {th }}$ September, 2017) with $\mathrm{VV}_{\text {Min }}$ values in these dates could well be utilized in classification of maize which differed from cotton, an another major crop grown in these districts during the season sown 30 days before the date of maize sowing $9^{\text {th }}$ to $21^{\text {st }}$ August, 2017). All the six-multi temporal features concisely characterized the key information in the maize signature. Hence, the values of multi-temporal features derived were used in classification of maize pixels in the study area and maize area map was generated which was in line with work reported by Pazhanivelan et al. (2015).

\subsection{Maize area and accuracy assessment}

Through classification, the information content of the image was simplified into a thematic map and could therefore be easily interpreted by the end user. Based on the classified map, further properties of the different classes were derived and several considerations were given. The maximum likelihood classifier was adopted in this study for extracting information from multitemporal SAR data. The results obtained were compared and presented. Maize area map (Figure 2) for the study area was derived from multi-temporal SAR imagery of Sentinel $1 \mathrm{~A}$. Using the shape files of administrative boundaries block wise maize area maps and statistics were extracted for Alathur, Perambalur, Veppanthattai and Veppur blocks of Perambalur and Andimadam, Ariyalur, Jayamkondam, Sendurai, T.Palur and Thirumanur blocks of Ariyalur district. Area under maize 
cultivation in the study region was classified using parameterized classifier integrated with multi-temporal features and the area map was generated.

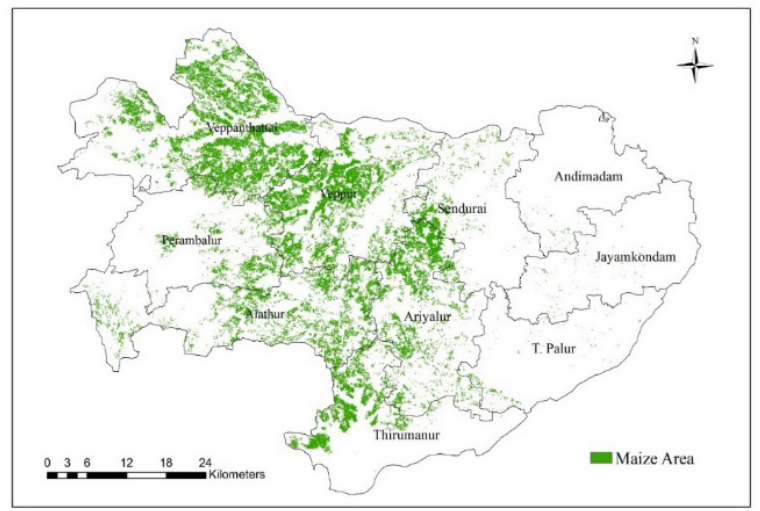

Figure 2. Maize area map

The maize area in Perambalur and Ariyalur districts were 41632 and 14236 ha respectively (Table 1). A total of 55868 ha of maize in the study area of these two districts out of 3.4 Lakhs ha of general maize area in Tamil Nadu indicates the importance of this region in maize production. Veppanthattai block of Perambalur district recorded the highest maize area of 16342 ha among the four blocks in the district might have been due to the favorable rainfall of $>900 \mathrm{~mm}$ and black soils with high water holding capacity. The lowest maize area was recorded in Perambalur block of the district. Whereas in Ariyalur district the highest maize area was recorded in Ariyalur block (6727 ha) followed by Thirumanur (4330 ha) and Sendurai (2184 ha) blocks indicating the dominance of these blocks cultivating maize traditionally.

The accuracy of the classification was assessed using the ground truth points collected during the crop-growing season in the study area. The overall accuracy of the maize area map was 91 percent with the reliability of 91.1 percent. The kappa score was 0.82 .

\begin{tabular}{|l|l|r|}
\hline \multirow{4}{*}{ District } & \multicolumn{1}{|c|}{ Block } & Area (ha) \\
\hline \multirow{4}{*}{ Perambalur } & Veppanthattai & 16342 \\
\cline { 2 - 3 } & Veppur & 12753 \\
\cline { 2 - 3 } & Perambalur & 3746 \\
\cline { 2 - 3 } & Alathur & 8971 \\
\cline { 2 - 3 } & \multicolumn{1}{|c|}{ Total Area } & $\mathbf{4 1 6 3 2}$ \\
\hline \multirow{5}{*}{ Ariyalur } & Andimadam & 261 \\
\cline { 2 - 3 } & Sendurai & 2184 \\
\cline { 2 - 3 } & Jayamkondam & 198 \\
\cline { 2 - 3 } & Ariyalur & 6727 \\
\cline { 2 - 3 } & T. Palur & 536 \\
\cline { 2 - 3 } & Thirumanur & $\mathbf{1 4 2 3 6}$ \\
\cline { 2 - 3 } & & Total Area \\
\hline
\end{tabular}

Table 1. Block wise maize area for Ariyalur and Perambalur districts

\section{CONCLUSION}

Spectral $\mathrm{dB}$ curve of maize derived from multi-temporal Sentinel 1A data showed minimum at sowing and maximum at the vegetative to tasseling stage of the crop with $\mathrm{dB}$ values of 21.26 to -13.18 in $\mathrm{VH}$ polarization and -14.05 to -6.54 in VV polarization. Maize area map was generated with the overall classification accuracy of 91 percent and kappa score of 0.82 . The total maize area of Ariyalur and Perambalur districts were 14236 and $41632 \mathrm{~kg} \mathrm{ha}^{-1}$ respectively during kharif 2017 . The higher accuracies of the maize area during the cropping season dominated by other crops viz., cotton and sorghum might have been due to use of multi-temporal features from $\mathrm{S}_{1} \mathrm{~A}$ GRD data with $20 \mathrm{~m}$ resolution and coherences from $\mathrm{S}_{1} \mathrm{~A}$ SLC data of $5 \mathrm{~m}$ resolution. Especially the $\mathrm{VV}_{\mathrm{Min}}$ at seedling stage, $\mathrm{VH}_{\mathrm{Max}}$ at tassel initiation stage might have helped precise spectral discrimination of maize from other crops while $\mathrm{VV}_{\text {MinDate }}$ and coherence features might have resulted in temporal discrimination of maize from cotton, which were sown at 30-40 days interval. The high accuracy of classification in the study area demonstrated that the methodology was appropriate for maize area estimation using multi-temporal Sentinel 1A data.

\section{REFERENCE}

Aspert, F., Bach-Cuadra, M., Cantone, A., Holecz, F. and Thiran, J.P., 2007. Time-varying segmentation for mapping of land cover changes. In ENVISAT Symposium (No. EPFLCONF-104974).

Blaes, X., Defourny, P., Wegmuller, U., Della Vecchia, A., Guerriero, L. and Ferrazzoli, P., 2006. C-band polarimetric indexes for maize monitoring based on a validated radiative transfer model. IEEE transactions on geoscience and remote sensing, 44(4), pp.791-800.

Foo, B.Y. and Eom, H.J., 1987. Interpretation of the polarimetric co-polarization phase tern in radar images obtained with the JPL airborne L-band SAR system. IEEE Transactions on Geoscience and Remote Sensing, (1), pp.77-82.

De Grandi, G.F., Leysen, M., Lee, J.S. and Schuler, D., 1997, August. Radar reflectivity estimation using multiple SAR scenes of the same target: technique and applications. In Geoscience and Remote Sensing, 1997. IGARSS'97. Remote Sensing-A Scientific Vision for Sustainable Development., 1997 IEEE International Vol. 2, pp. 1047-1050, IEEE.

Gómez-Chova, L., Tuia, D., Moser, G. and Camps-Valls, G., 2015. Multimodal classification of remote sensing images: A review and future directions. Proceedings of the IEEE, 103(9), pp.1560-1584.

Holecz, F., Barbieri, M., Collivignarelli, F., Gatti, L., Nelson, A., Setiyono, T.D., Boschetti, M., Manfron, G., Brivio, P.A., Quilang, J.E. and Obico, M.R., 2013, September. An operational remote sensing based service for rice production estimation at national scale. In Proceedings of the living planet symposium.

Hoogeboom, P. 1983. Classification of agricultural crops in radar images. IEEE Transactions on Geoscience and Remote Sensing, 21: 329-336.https://scihub.copernicus.eu/dhus/

Inoue, Y., Sakaiya, E. and Wang, C. 2014. Capability of C-band backscattering coefficients from high-resolution satellite SAR sensors to assess biophysical variables in paddy rice. Remote Sensing of Environment, 140, pp. 257-266. 
Lillesand, T. M. and Kiefer, R. W. 1994. Remote sensing and photo interpretation. John Wiley and Sons: New York, pp.750.

Macelloni, G., Paloscia, S., Pampaloni, P., Marliani, F. and Gai, M., 2001. The relationship between the backscattering coefficient and the biomass of narrow and broad leaf crops. IEEE Transactions on Geoscience and Remote Sensing, 39(4), pp. 873-884.

McNairn, H., Kross, A., Lapen, D., Caves, R. and Shang, J., 2014. Early season monitoring of corn and soybeans with TerraSAR-X and RADARSAT-2. International Journal of Applied Earth Observation and Geoinformation, 28, pp. 252259.

Nelson, A., Setiyono, T., Rala, A.B., Quicho, E.D., Raviz, J.V., Abonete, P.J., Maunahan, A.A., Garcia, C.A., Bhatti, H.Z.M., Villano, L.S. and Thongbai, P., 2014. Towards an operational SAR-based rice monitoring system in Asia: Examples from 13 demonstration sites across Asia in the RIICE project. Remote Sensing, 6(11), pp. 10773-10812.

Panigrahi, R.K. and Mishra, A.K., 2013. Unsupervised classification of scattering behavior using hybridpolarimetry. IET Radar, Sonar \& Navigation, 7(3), pp. 270-276.

Pazhanivelan, S., Kannan, P., Mary, N., Christy, P., Subramanian, E., Jeyaraman, S., Nelson, A., Holecz, F. and Yadav, M., 2015. Rice crop monitoring and yield estimation through cosmo skymed and terrasar-x: a sar-based experience in india. International Archives of the Photogrammetry, Remote Sensing \& Spatial Information Sciences.

Shewalkar, P., Khobragade, A. and Jajulwar, K., 2014. Review paper on crop area estimation using SAR remote sensing data. IOSR J. Electr. Electron. Eng, 9, pp. 97-98.

Waldhoff, G., Curdt, C., Hoffmeister, D. and Bareth, G., 2012. Analysis of multitemporal and multisensor remote sensing data for crop rotation mapping. ISPRS Ann. Photogramm. Remote Sens. Spatial Inf. Sci, 1, pp.7. 